\title{
MASSETOGNATHUS (CYNODONTIA, TRAVERSODONTIDAE) FROM THE SANTA MARIA FORMATION OF BRAZIL
}

\author{
JUN LIU \\ Institute of Vertebrate Paleontology and Paleoanthropology, Chinese Academy of Sciences, Beijing, 100044 China. \\ liujun@ivpp.ac.cn \\ MARINA BENTO SOARES \& MIRIAM REICHEL \\ Departamento de Paleontologia e Estratigrafia, UFRGS, Porto Alegre, RS, Brazil.marina.soares@ufrgs.br
}

\begin{abstract}
Based on a new examination of published specimens and some unstudied specimens from Brazil, Massetognathus ochagaviae is re-evaluated and the diagnosis revised. One distinguished character of this species not previously mentioned is the base lateral to the labial margin of upper postcanines extending outward to form an isosceles triangle in occlusal view. It also differentiates from Massetognathus pascuali by having a higher skull and mandible, slightly dorsally pointed dentary ventral border under the coronoid process, less variable number of postcanines, nearly triangular basin on the upper canines due to the short lingual ridge, robust lower canines, and subrectangular shaped lower postcanines. The ontogenetic variation within Massetognathus ochagaviae is discussed and compared with M. pascuali. All Brazilian specimens of Massetognathus other than MCP 3284PV are referred to as M. ochagaviae. The specimen MCP $3871 \mathrm{PV}$ is designated as neotype for Massetognathus ochagaviae.
\end{abstract}

Key words: Cynodontia, Traversodontidae, Massetognathus ochagaviae, Massetognathus pascuali, Brazil.

RESUMO - Com base em novas observações feitas nos espécimes publicados e no estudo de espécimes brasileiros inéditos, Massetognathus ochagaviae é reestudado e sua diagnose revisada. Um distintivo caráter desta espécie, não mencionado previamente, consiste na base labial dos pós-caninos superiores se projetando lateralmente e formando um triângulo isósceles em vista oclusal. O táxon estudado também se diferencia de Massetognathus pascuali por apresentar crânio alto, mandíbula com a borda ventral do dentário, situada abaixo do processo coronóide, levemente direcionada dorsalmente, menor variação no número de pós-caninos, base dos caninos superiores quase triangular devido à curta crista lingual, caninos inferiores robustos e pós-caninos inferiores com forma sub-retangular. A variação ontogenética de M. ochagaviae é discutida e comparada com a de M. pascuali. Todos os espécimes brasileiros de Massetognathus, com exceção de MCP 3284-PV, são atribuídos a M. ochagaviae.

Palavras-chave: Cynodontia, Traversodontidae, Massetognathus ochagaviae, Massetognathus pascuali, Brasil.

\section{INTRODUCTION}

The genus Massetognathus was established by Romer (1967) based on the material collected from the Chañares Formation of Argentina. He named three species under this genus: Massetognathus pascuali, M. teruggi and M. major; later he also named another taxon, Megagophodon oligodens, from the same locality (Romer, 1967, 1972). All these species were suggested as being synonymous, with the only valid species being Massetognathus pascuali (Abdala \& Giannini, 2000; Battail, 1991). Barberena (1981) named another species, Massetognathus ochagaviae on the basis of a specimen from the Santa Maria Formation, Rio Grande do Sul, Brazil (Figure 1; Barberena, 1981:figs. 1-5). In 1981, he listed the following characters in the diagnoses of $M$. ochagaviae: "Gomphodont cynodont with cranial length of $12.7 \mathrm{~cm}$, largely compressed; snout widened; orbits sub-circular, more dorsal than other species; interorbital region large; 4 incisors beveled on premaxilla; tooth rows smoothly curved; maxillary postcanines bigger than those of Massetognathus pascuali and M. teruggi; "shouldering" less than that of Exaeretodon; 11-12 maxillary postcanines; transverse edge separated a small posterior cavity in the 9th postcanine." Later, Sá Teixeira (1987) described a well-preserved specimen of Massetognathus ochagaviae, in which her diagnoses were similar to those of Barberena (1981). However, most of these characters are also present in Massetognathus pascuali, and the presence of the posterior cavity was not confirmed. In the holotype of Massetognathus ochagaviae, the size of the postcanines cannot really differ from that of $M$. pascuali with similar skull size. This species is invalid on the basis of these diagnoses.

Based on our observation, Massetognathus ochagaviae really has some distinct characters to validate it as a separate 
species, especially the morphology of the postcanine teeth, which is not mentioned by the previous researcher but can be observed on the original drawings of Barberena (1981). In this paper, we designate the well-preserved specimen MCP 3871-PV as a neotype for $M$. ochagaviae since the original holotype was lost in the 1990s (verbal information of C. Schultz, UFRGS collection curator). Based on the comparison with some other specimens, the intra-species variation is discussed.

Institutional abbreviations. AMNH, American Museum of Natural History, New York; MCZ, Museum of Comparative Zoology, Cambridge; MCP, Museu de Ciências e Tecnologia, Pontificia Universidade Católica do Rio Grande do Sul, Porto Alegre; PULR, Museo de Antropología, Universidad Nacional de La Rioja, La Rioja; PVL, vertebrate paleontology, Instituto Miguel Lillo, Universidad Nacional de Tucumán, Tucuman; UFRGS, paleovertebrate collection, Instituto de Geociências, Universidade Federal do Rio Grande do Sul, Porto Alegre.

Abbreviations used in figures. Bs, basisphenoid; Ep, epipterygoid; $\mathbf{F}$, frontal; fj, foramen jugulare; fo, fenestra ovalis; Ip, interparital; M, maxilla; N, nasal; L, lacrimal; $\mathbf{O p}$, opisthotic; P, parietal; PI, palatine; Po, postorbital; Pr, prootic; ppf, pterygoparoccipital foramen; pop, paraoccipital process; Pfr, prefrontal; Pr, prootic; Ps, parasphenoid; Pt, pterygoid; Q, quadrate; s.f, sphenoorbital fissure; Sm, septomaxilla; So, Supraoccipital; Sq, squamosal; T, tabular; $\mathbf{V}$, vomer.

\section{SYSTEMATIC PALEONTOLOGY}

TRAVERSONODONTIDAE von Huene, 1936
Massetognathus Romer, 1967
Massetognathus ochagaviae Barberena, 1981

(Figures 1-7)

Neotype. MCP 3871-PV, a well-preserved skull.

Remarks on type material. MCP 3871-PV is the specimen described by Sá Teixeira (1987), but she mislabeled it as MCP $1600-\mathrm{PV}$, which is the number for the holotype of Probelesodon kitchingi. MCP 3871-PV is designated here to replace the holotype UFRGS-PV 0255T (lost).

Collecting site. Candelaria, Rio Grande do Sul, Brazil; Dinodontosaurus Zone, Santa Maria Formation (Ladinian, Middle Triassic).

Materials examined. UFRGS-PV0070T, 0071T, 0122T, 0125T, 0239T, 0241T, 0242T, 0243T, 0245T, 0246T, 0265T, 0273T, 0397T, 1064T; AMNH 7802, 7803, 21400-21410 collected by Colbert in 1959. All specimens were collected from the Santa Maria Formation, Rio Grande do Sul. Most specimens are only partly prepared.

Emended diagnosis. A traversodontid differing from Massetognathus pascuali by having a higher skull and mandible, slightly dorsally pointed dentary ventral border under the coronoid process, less variable number of
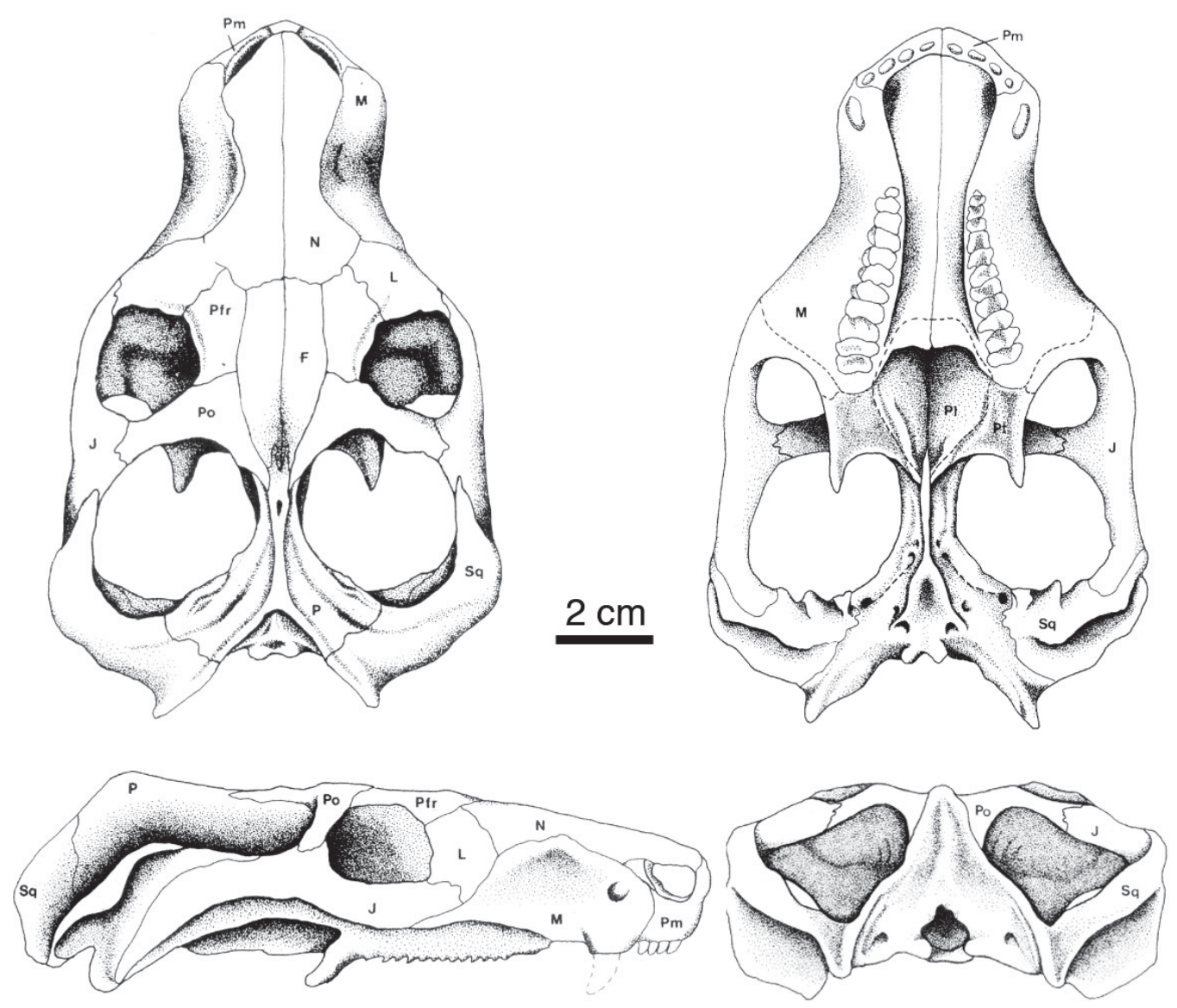

Figure 1. Original drawings of Massetognathus ochagaviae, UFRGS PV 0255T(G; holotype), from the Santa Maria Formation (Ladinian) of Rio Grande do Sul State, Brazil (from Barberena, 1981). 

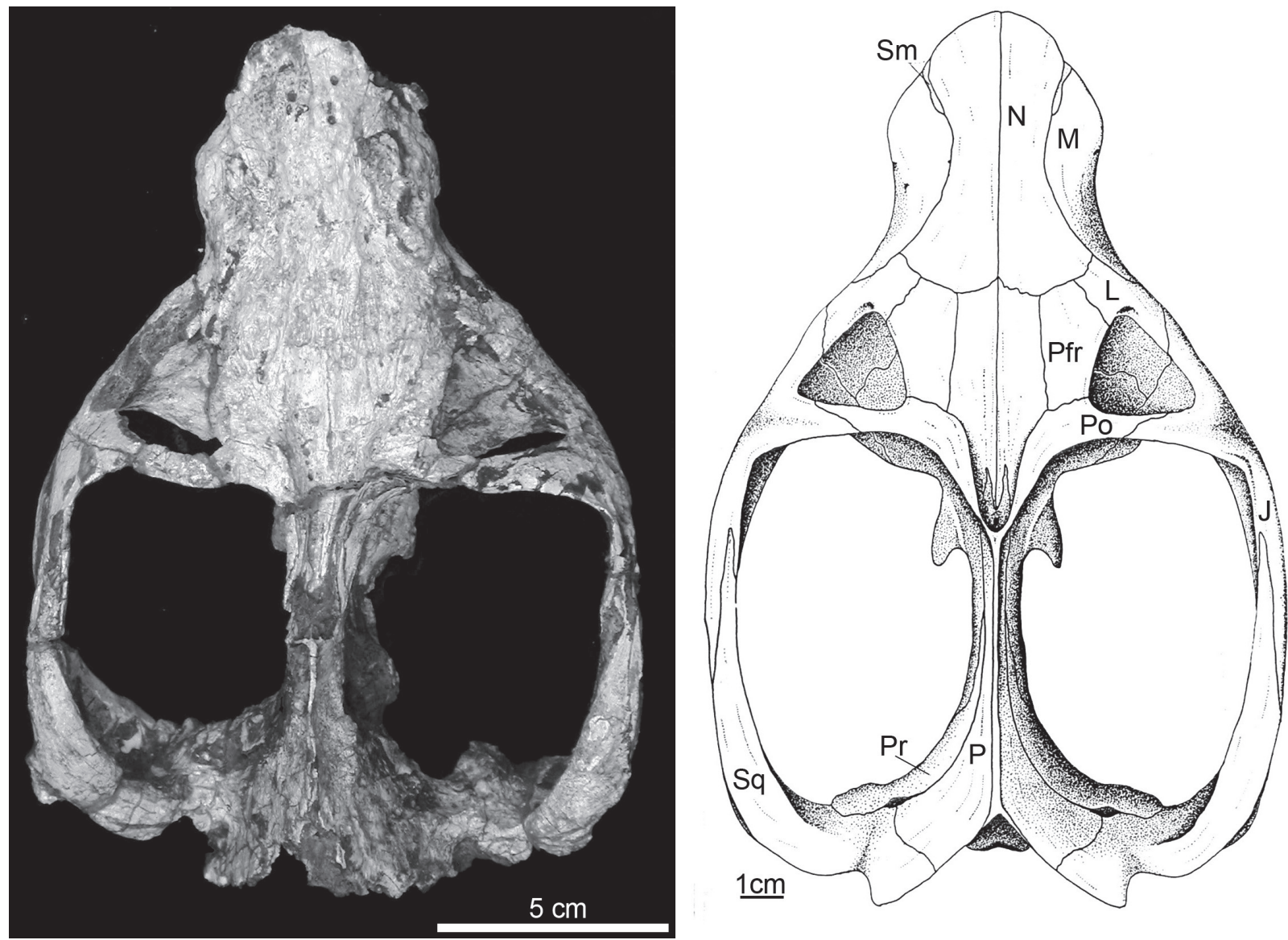

Figure 2. Massetognathus ochagaviae, MCP 3871-PV, neotype, photo and reconstruction of skull in dorsal view (reconstruction modified from Sá Teixeira, 1987:fig. 1).

postcanines, the base lateral to the labial margin of the upper postcanines extending outward to form an isosceles triangle in occlusal view, nearly triangular basin on the upper canines due to the short lingual ridge, robust lower canines, and subrectangular shaped lower postcanines.

\section{Description}

The holotype, UFRGS-PV 0255T (G), is a nearly complete skull (Figure 1). However, it was lost in the 1990s. Without specific mention, the following description of the skull is mainly based on a well-preserved specimen, MCP 3871-PV (Figures 2-5).

Skull. The basal cranial length of Massetognathus pascuali ranges from 6 to $21 \mathrm{~cm}$, but most known specimens are less than $12 \mathrm{~cm}$ (Romer, 1972). However, all known specimens from Brazil have a basal cranial length greater than $12 \mathrm{~cm}$, reaching $31 \mathrm{~cm}$ in UFRGS PV0122T (Table 1).

The holotype measured only $127 \mathrm{~mm}$ in basal cranial length, and therefore belongs to a small individual, and at most a sub-adult. The basic pattern of bone sutures of Massetognathus ochagaviae is similar to that of M. pascuali, but there is some difference in the gross shape of the skull. The skull is relatively broad with swollen snout, more robust than Massetognathus pascuali. The height of the skull is generally greater rather than that of Massetognathus pascuali, and the parietal region directs more upward than the latter.
This is more notable in larger specimens, and can be attributed to ontogeny, because the height of the occipital region shows positive allometric growth in comparison to the basal cranial length (see the discussion below).

The premaxillae contact the nasals to form a complete internarial bar. The maxillae are greatly expanded laterally; they are located far beyond the line of the tooth row, especially on the snout. In lateral view, the maxillae overlap the premaxillae above the canine. In some specimens such as MCP 3871-PV, AMNH 7803, UFRGS-PV0245T, the toothbearing part of maxillae directs somewhat ventrally and slightly convex, increasing the height of the skull. However, it is relatively flat in the holotype based on figure 2 of Barberena (1981) (Figure 1). This part is straight and nearly parallel to the ventral margin of the zygomatic arch in most specimens of Massetognathus pascuali, although it is also slightly convex in a few specimens such as PVL 4728.

The orbits face not only laterally but also dorsally and slightly anteriorly. Below the orbit, the jugal deflects ventrally, so that the zygomatic arch is convex upward. The tall zygomatic arches, which are mainly composed of the jugal, are widely expanded in a line nearly parallel to the long axis of the skull. The squamosal only contributes to the posterior and upper border. The jugal suborbital process is absent. It is difficult to judge the presence of the parietal foramen. In the holotype, it was not possible to observe the parietal foramen due to a 

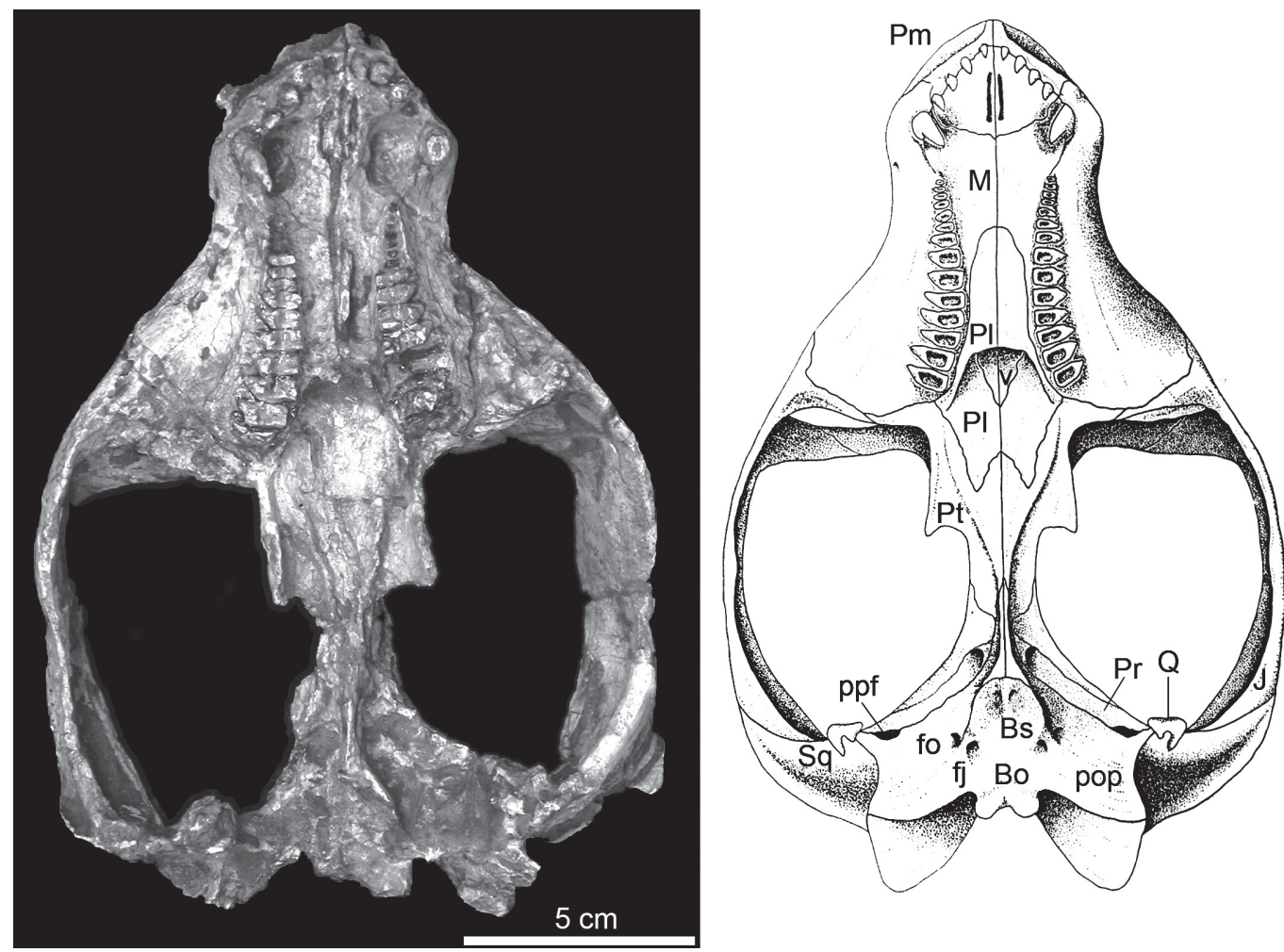

Figure 3. Massetognathus ochagaviae, MCP 3871-PV, neotype, photo and reconstruction of skull in ventral view (the reconstruction modified from Sá Teixeira, 1987:fig. 2).

fracture in the intertemporal region of the skull (Barberena, 1981). Even if it is present as suggested by Sá Teixeira (1987), it is quite a small foramen anterior to the parietal ridge.

The premaxillae extend posteriorly to the level of the canines on palate, completely enclosing the incisive foramina. In the holotype of Massetognathus pascuali (PURL 10), this part is covered by the lower jaw. However, the specimen
UFRGS-PV 0968T shows similar suture pattern based on the observation of the senior author. The secondary palate, which is formed by the maxillae and the palatines, extends posteriorly to the level around the second and the third postcanines counting backward, beyond the anterior border of the orbit. The palatines anteriorly reach around half the length of the secondary palate. This differs appreciably from the bone

Table 1. Measurements (mm) of Massetognathus specimens from Brazil . Abbreviations: TL, skull total length, from the anterior tip to the occipital condyles; MUL, muzzle length; BW, maxillary bicanine width; PAL, palate length; UP, upper postcanine tooth row length; TEL, total temporal region length; SW, maximum skull width; $\mathbf{Z H}$, maximum height of the zygomatic arch; IO, interorbital distance; OL, orbital length; OD, orbital diameter; BB, basicranial length; $\mathrm{OH}$, height of the occipital plate; OW, occipital plate width; POW, skull width at postorbital bar.

\begin{tabular}{|c|c|c|c|c|c|c|c|c|c|c|c|c|c|c|c|}
\hline & $\overline{\mathrm{TL}}$ & MUL & $\overline{B W}$ & $\overline{P A L}$ & UP & $\overline{\text { TEL }}$ & SW & $\overline{\mathrm{ZH}}$ & 10 & $\overline{\mathrm{OL}}$ & OD & $\overline{B B}$ & $\overline{\mathrm{OH}}$ & OW & POW \\
\hline UFRGS-PV0122T & 310 & 115 & 100 & 130 & 72 & 135 & 250 & 96 & 100 & 63 & & 63 & 133 & 124 & 255 \\
\hline UFRGS-PV0125T & 225 & 82 & 76 & 98 & 50 & 83 & 127 & 64 & 68 & 36 & 35 & 61 & 108 & & 120 \\
\hline UFRGS-PV0241T & 145 & 53 & 52 & 66 & 42 & 46 & 107 & 34 & 39 & 28 & 32 & 28 & 59 & 63 & 107 \\
\hline UFRGS-PV0242T & 194 & 70 & 62 & 88 & 53 & 70 & 135 & 52 & 41 & 41 & 34 & 41 & 72 & 64 & 130 \\
\hline UFRGS-PV0243T & 181 & 67 & 60 & 72 & 55 & 75 & 137 & 52 & 46 & 31 & 33 & 30 & 73 & 58 & 118 \\
\hline UFRGS-PV0245T & 194 & 75 & 66 & 79 & 50 & 73 & 165 & 68 & 77 & 32 & 25 & & & 80 & 148 \\
\hline UFRGS-PV0255T & 127 & 57 & 40 & 63 & 37 & 35 & 88 & 29 & 31 & 25 & & & 35 & 38 & 80 \\
\hline AMNH 7803 & 150 & 68 & 47 & 71 & 57 & 37 & 116 & 48 & 39 & 34 & & & 61 & 64 & 110 \\
\hline AMNH 21400 & 140 & 60 & 46 & 64 & 45 & 47 & 98 & & 35 & 25 & 19 & & & & 96 \\
\hline AMNH 21404 & 148 & 67 & 46 & 75 & 52 & 44 & & & 38 & 26 & 20 & 34 & 63 & 64 & \\
\hline AMNH 21401 & 157 & 77 & 50 & 82 & & 49 & 126 & 60 & 52 & 33 & 21 & & 68 & 76 & \\
\hline MCP 3871PV & 170 & 60 & 48 & 69 & 43 & 78 & 125 & 38 & 40 & 31 & 30 & 31 & 52 & 54 & 120 \\
\hline MCP 3284PV & 155 & 55 & 39 & 63 & & 68 & & & 43 & 29 & 28 & 28 & & & \\
\hline
\end{tabular}



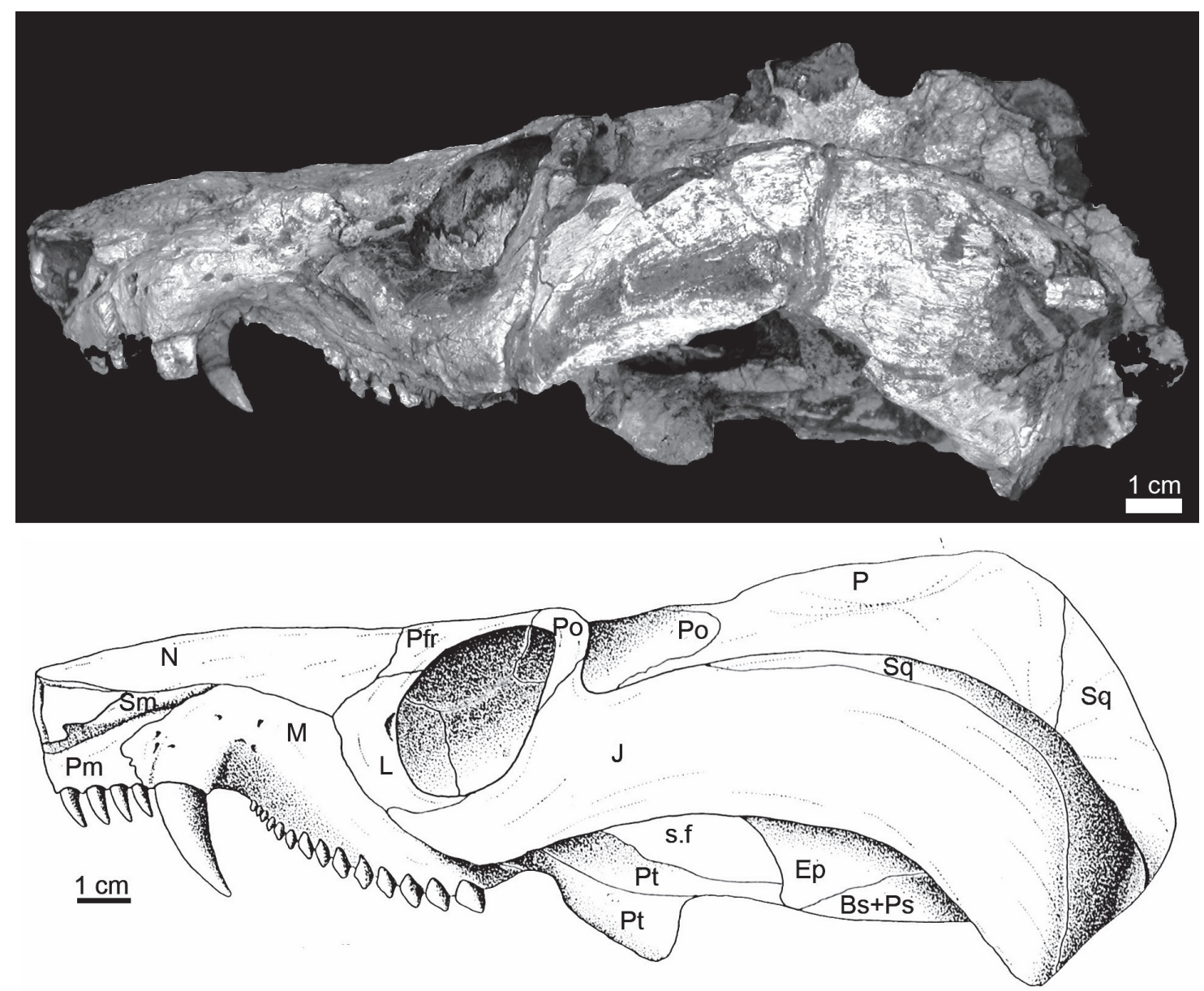

Figure 4. Massetognathus ochagaviae, MCP 3871-PV, neotype, photo and reconstruction of skull in lateral view (the reconstruction modified from Sá Teixeira, 1987:fig. 3).

pattern described for Massetognathus pascuali by Romer (1967).The lacrimal occupies much of the anterior margin of the orbital rim, and forms a portion of the ossified anterior surface of the orbital socket, between the prefrontal above and the jugal below. It extends ventrally to contact the orbital process of the palatine. There is a long but low gap, sphenoorbital fissure, in the medial wall of the braincase. The orbitosphenoid is ossified above it. The two orbitosphenoids meet ventrally, forming the floor and the lateral wall of the anterior portion of the braincase (olfactory portion of the brain). Behind it, the expanded epipterygoid (alisphenoid) lies between parietal dorsally and pterygoid ventrally. Its anterodorsal process touches the ventral side of the frontal. Posteriorly, the epipterygoid keeps contact with the anterior margin of the prootic. Located in the epipterygoid-prootic suture is the trigeminal foramen $\left(\mathrm{V}_{2+3}\right)$. The prootic, besides the suture with the epipterygoid, is separated from the squamosal and the parietal by the sinus canal. Ventrally, the prootic encloses most of the pterygoparoccipital foramen.

Lower jaw. Similar to the skull, the lower jaw looks more robust than that of Massetognathus pascuali (Figure 6). The dentary is well developed, with a high and broad coronoid process. In Massetognathus pascuali, the ventral margin of the dentary is nearly straight or slightly smoothly convex. In
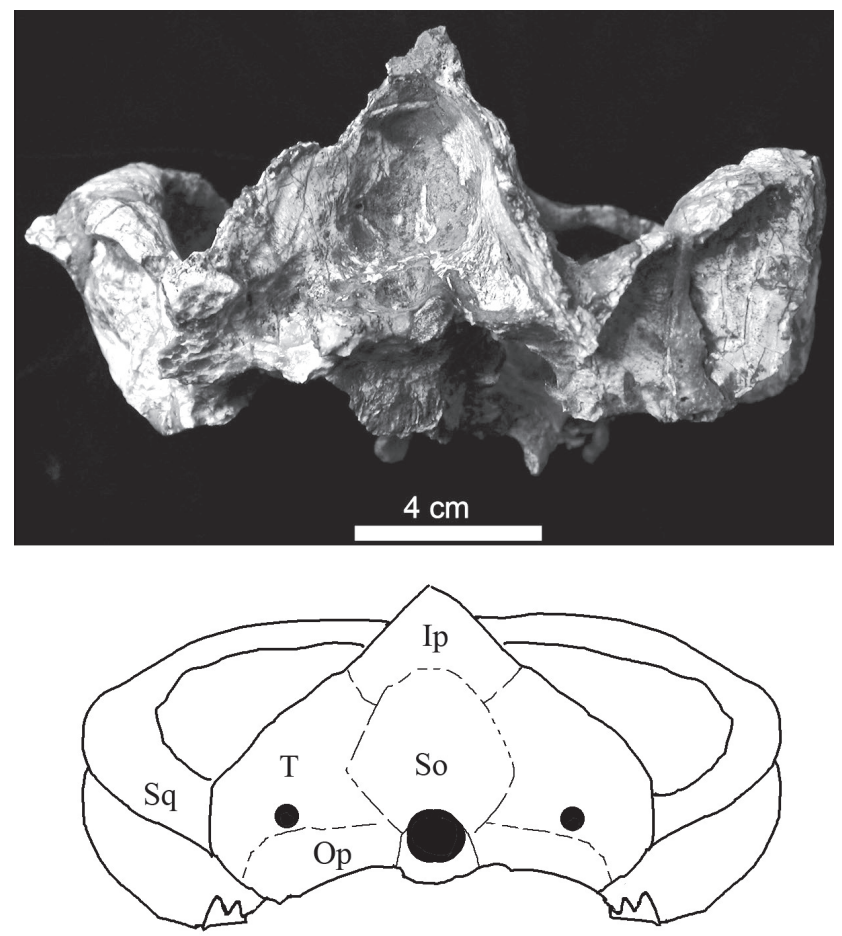

Figure 5. Massetognathus ochagaviae, MCP 3871-PV, photo and reconstruction of skull in occipital view. 


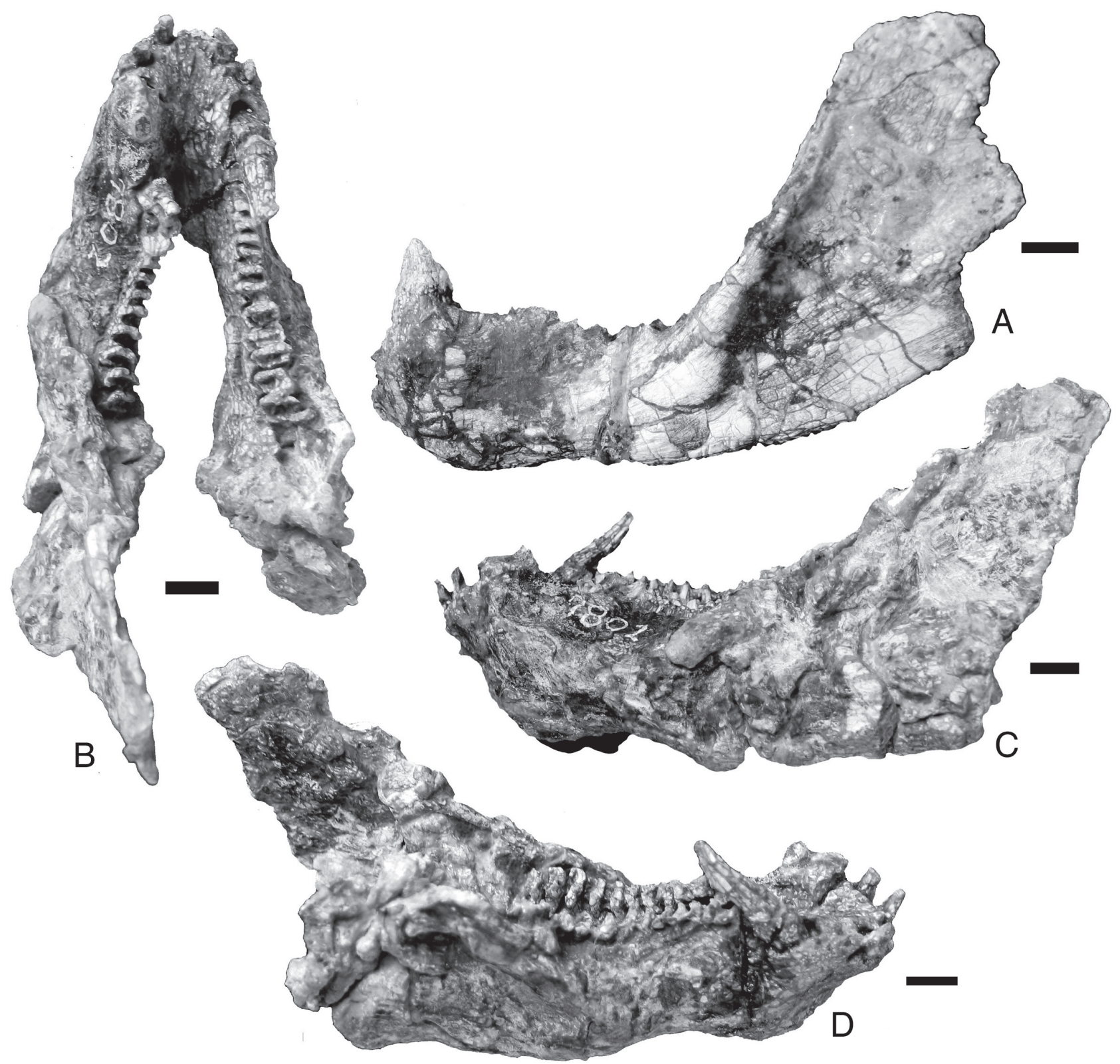

Figure 6. Lower jaws of Massetognathus ochagaviae. A, UFRGS PV 1064T in lateral view; B-D, AMNH 7802 in occlusal (B), lateral (C) and medial (D) views. Scale bars $=1 \mathrm{~cm}$.

Massetognathus ochagaviae, the posterior part turns upwards, forming an obtuse angle under the place of the rising of the coronoid process. The coronoid process is a thin plate, thickened along its anterior margin. It looks more vertical than that of Massetognathus pascuali. As generally seen in gomphodont cynodonts, the anterior margin is nearly straight, and the dorsal margin is rounded. From the tip of the coronoid process, the posterior margin extends downward toward the articular area, curving forward, and it is nearly vertical rather than posterodorsally directed, so that the coronoid process extends only slightly posteriorly beyond the ventral boundary. These result in a slightly wider coronoid process. The posterior process of the dentary strongly expands dorsoventrally but not posteriorly, where the angular process is thick and round with no posterior projection. The masseter fossa is well developed. The relation of the dentary to other mandibular bones posteriorly is obscure, where only the inner concave area shows the presence of these bones. Dentition. As generally in gomphodonts, four upper and three lower incisors are developed on each side of the jaw. The incisors are somewhat lateral-compressed and of moderate size; the first one is more like a chisel. All upper incisors are remarkably curved backward.

There should be only one canine on each maxilla of traversodontids, but two packed upper canines of similar size grow anteroposteriorly in the left canine alveolus of AMNH 7803, but only one is present in all others. It is possibly due to the keeping of unshed replaced canines. The upper canines are relatively little developed, only slightly larger than the incisors. The lower canines are well developed. The 


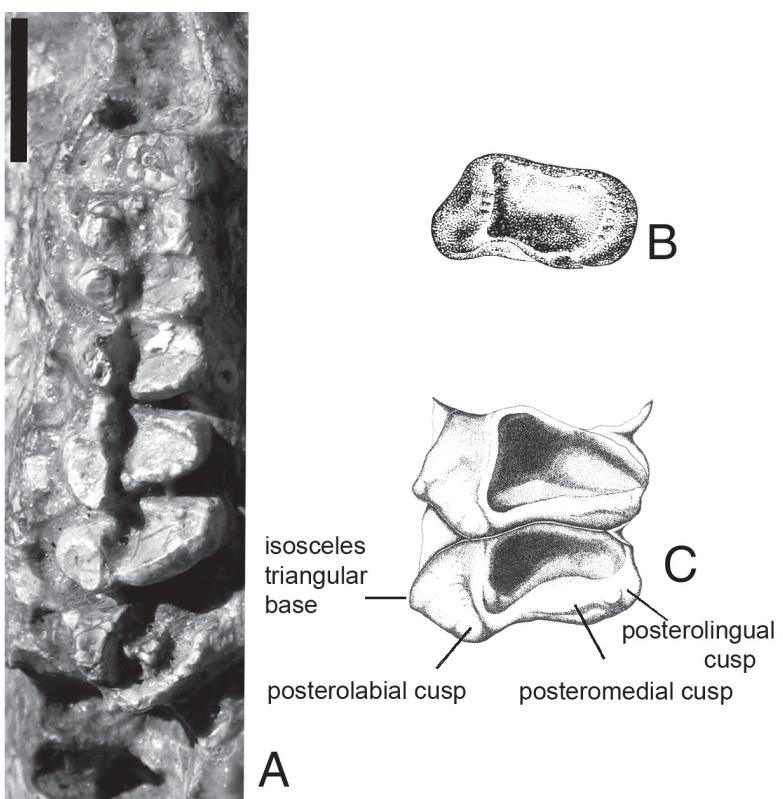

Figure 7. Massetognathus upper postcanine teeth in occlusal view: A, $M$. ochagaviae, UFRGS-PV 0245T, right side; B, drawing of $M$. pascuali (from Romer, 1967:fig. 5A); C, drawing of $M$. ochagaviae (modified from Baberena, 1981:fig. 5). Scale bars $=1 \mathrm{~cm}$.

right canine is $25 \mathrm{~mm}$ above the dentary in AMNH 7802 while the lower incisors are less than half of this height.

In the holotype, there is a distinct diastema between the canine and anteriormost postcanine on the skull (Figure 1). In larger specimens, the diastema is still present but relatively small. The number of upper postcanines is 12 and 11 respectively on the left and right side on the holotype; and is as high as 14 in the specimen MCP 3871-PV. For all other specimens where the teeth can be counted, the number falls within this range.

The upper postcanine tooth rows are slightly convex medially; the distance between two rows is widest on the posteriormost part. The size of postcanines increases backward, reaching a maximum in the penultimate or the tooth anterior to it, and then decreases slightly in last one or two teeth. For example, in AMNH 7803, the first tooth is less than $6 \mathrm{~mm}$ in width, the 10th is $13.8 \mathrm{~mm}$ in width, and the last one
$13.3 \mathrm{~mm}$, measured on the left side.

The upper postcanines of the referred specimens have the same shape as the holotype of Massetognathus ochagaviae (Figures 3,7). Its lingual margin is curved and short, giving a subtriangular or long oval shape in occlusal view. The mesial margin is slightly convex in outline, and the distal margin is nearly transverse but slightly concave posteriorly, so that each tooth shoulder is to a slight degree into the area of its next mesial neighbor. On the labial border, the base of the cone forming the posterolabial cusp extends considerably outward and forward, and looks like it is shared with the minor anterolabial cusp, forming an isoscelestriangular area lateral to the labial ridge, so that the labial border is two lines rather than nearly a diagonal line in Massetognathus pascuali (Figure 7B). This was shown in figure 5 of Barberena (1981) but not mentioned in his description. In Massetognathus pascuali, the distolabial corner is more developed and the same area on the labial border nearly forms a right triangle.

Two cusps develop on the labial portion of the tooth. The distal one is more prominent, the mesial one is slightly separated on the slope. The labial ridge is flat mesially. Lingual to the cusps, the labial ridge descends abruptly into a basin which occupies the center of the crown. The deepest area of the basin is close to the labial side, just anterior to the bent point on distal ridge.

The distal ridge is composed labially by a posterolabial cusp, lingually by two closely arranged cusps at the posterolingual corner. With wear, a clear wear facet is formed on the posterolabial cusp, and a deep groove cuts the mesial and distal ridges and connects with neighboring teeth (Figure 7A). The wear facets are observed on most postcanines other than few newly erupted teeth.

There is no distinct diastema between the canine and postcanines in the lower jaw. The number of lower postcanines is 12 on each side of AMNH 7802. The last postcanine is concealed by the coronoid process in lateral view. The width of postcanines gradually increases backward, from less than $4 \mathrm{~mm}$ in front to more than $7 \mathrm{~mm}$ in posterior of the tooth row, but the last two postcanines are slightly narrower than the $10^{\text {th }}$ postcanine. The width is at least 1.5
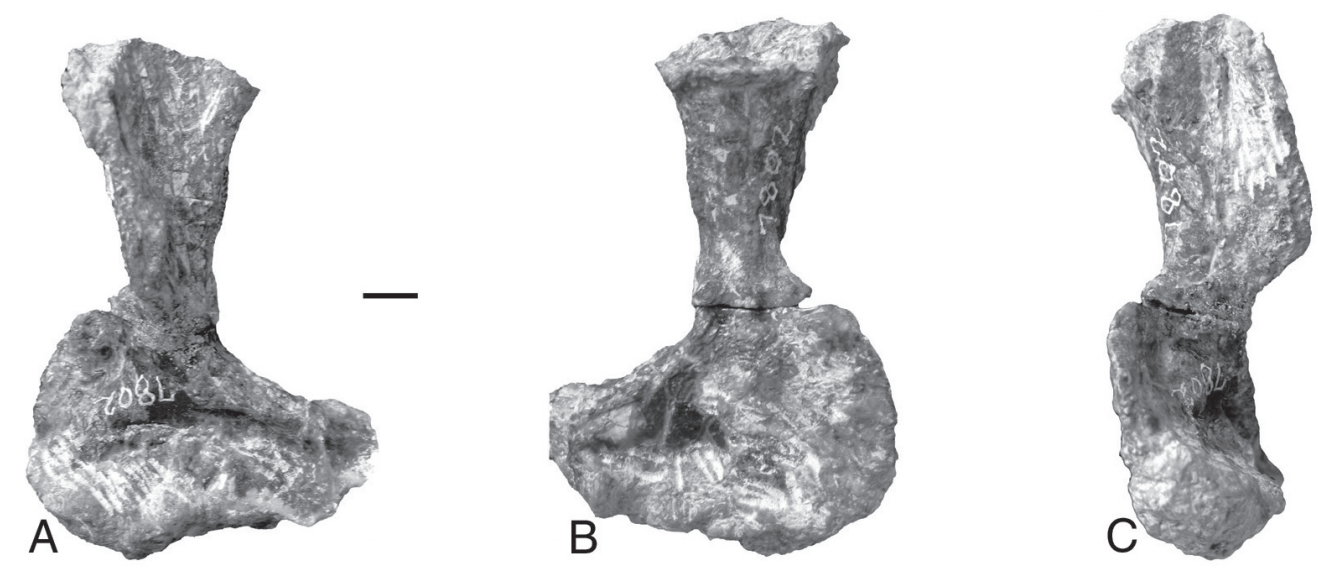

Figure 8. Right humerus of Massetognathus ochagaviae, $\mathrm{AMNH} 7802$, in ventral $(\mathbf{A})$, dorsal $(\mathbf{B})$, and anterior $(\mathbf{C})$ views. Scale bar $=1 \mathrm{~cm}$. 
times the length in posterior postcanines, and the width of the posterior side is smaller than on the anterior side, so that the teeth are subrectangular in shape not subquadrate as in Massetognathus pascuali. In other prepared lower jaws, the postcanine teeth are lost or badly preserved. However, their number is also approximately 12 . The basic pattern of lower postcanines is same as that of Massetognathus pascuali (Figure 6). Two partially divided cusps stand in the anterior margin as a high transverse ridge; the labial cusp is higher, while the lingual one is a little bit more curved backward. The posterior surface of the anterior ridge descends abruptly into a smoothly concave basin. In the other three sides of the basin, the labial ridge is the highest and the lingual one the lowest.

Humerus. An isolated right humerus is associated with a lower jaw (AMNH 7802) (Figure 8). This humerus measures $86 \mathrm{~mm}$ in length, $38 \mathrm{~mm}$ in width on the proximal end, $59 \mathrm{~mm}$ in width on distal end. Even if accounting for the missing part, the maximum width between epicondyles is perhaps more than half of the length. It is robust, more similar to the humerus of Exaeretodon than that of Massetognathus pascuali described by Jenkins (1970).

The proximal side is incomplete. The deltopectoral crest forms a ventrally bowed free edge with rugosity; it abruptly terminates at a small marginal tuberosity in the middle of the humerus. A thin but prominent ridge runs proximal-distally on the anterior surface of the crest, it is explained as the ridge for the insertion of the teres minor by Jenkins (1971).

A remarkable protuberance develops on the posteromedial aspect of the shaft, forming a concave groove for muscle insertion. A supracondylar flange is distinctly convex, not straight, giving the distal end of the humerus a fan shape in dorsal view as in Exaeretodon (Bonaparte, 1963), not triangular like in Cynognathus although similar in size. This flange extends anteriorly as a crest and disappears at midshaft; it is not continuous with any dorsal ridge. An ectepicondylar foramen is present in Thrinaxodon, Cynognathus, and other traversonodontids (Bonaparte, 1963; Bonaparte, 1966; Jenkins, 1971), the concave area close

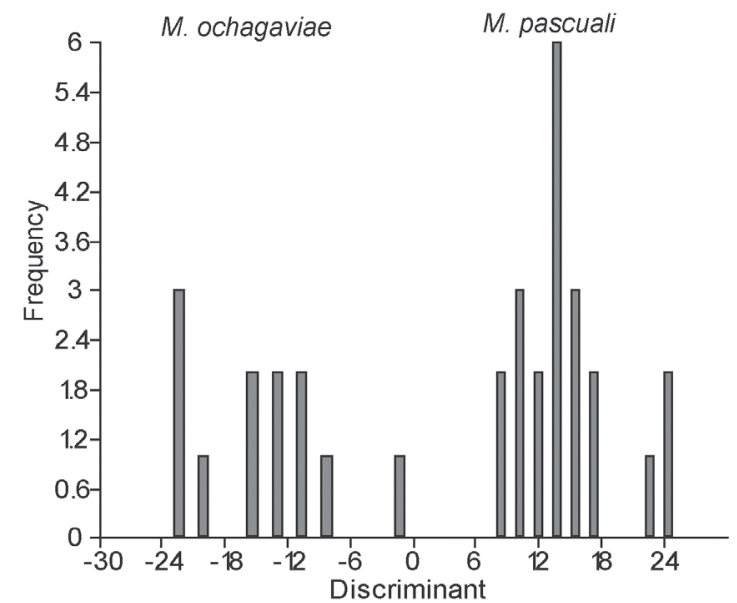

Figure 9. The discriminant analysis of two species of Massetognathus. $\mathrm{P}$ (same) under Hotelling's $\mathrm{T}^{2}$ test is $9.2 \mathrm{E}-7$. All the specimens are correctly classified.

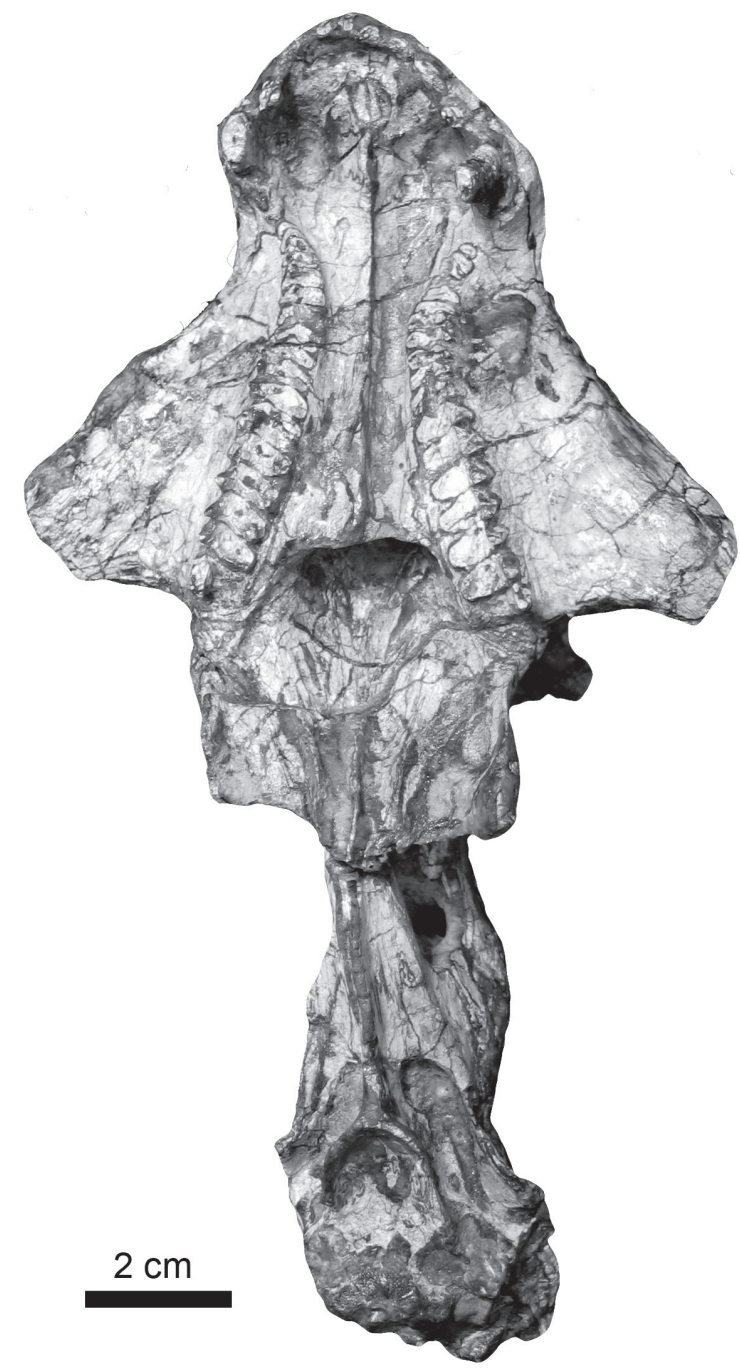

Figure 10. Skull of the only specimen of Massetognathus pascuali Romer from Brazil (MCP 3284-PV), identified by Sá Teixeira (1995) as Megagomphodont oligodens Romer, in ventral view.

to the anterior margin indicates its presence in this specimen. Because of the protrusion of the margin, the ectepicocondylar foramen has a farther distance to the margin compared to Cynognathus. The ectepicondyle is thicker than the entepicondyle, correlating with its position partially overlying the capitellum.

\section{ONTOGENETIC AND DISCRIMINANT ANALYSES OF SKULL}

Abdala \& Giannini (2000) studied the ontogenetic sequence of gomphodont cynodonts from the Chañares Formation. They recognized some allometric trends in the skull during growth, finding short, stocky skulls with large muzzles in small specimens, becoming slender skulls with small muzzles and large temporal fossae in large individuals. We wanted to test if the same ontogenetic trend is present in Massetognathus ochagaviae and if some differences mentioned in the description can be due to size differences, and therefore, similar measurements of the skull are used here. To be consistent with the previous study, we also used 
Table 2. Results of regressions on the total length of the skull. Abbreviations: $\mathbf{n}$, sample size; $\mathbf{a}(\mathbf{L S})$, coefficient of allometry calculated via least squares; a(MA), coefficient of allometry calculated via major axis method; $\log \mathbf{b}, \mathrm{y}$-intercept; $\mathbf{P}$, uncorrected P-value; $\mathbf{P}(\mathbf{a}=1)$, $P$-value for isometry; $\mathbf{R}^{2}$, coefficient of determination. Expected coefficient of allometry under isometry is 1.0 for all variables: ${ }^{* *}$ marginally significant; ${ }^{*}$ significant.

\begin{tabular}{|c|c|c|c|c|c|c|c|c|}
\hline & $\mathrm{n}$ & $a_{(L S)}$ & $\log b$ & $\mathbf{R}^{2}$ & $\mathbf{P}$ & $P(a=1)$ & $a_{\text {(MA) }}$ & $P(a=1)$ \\
\hline MUL & 12 & 0.73 & 0.46 & 0.78 & $<<0.001$ & 0.029 & 0.83 & 0.13 \\
\hline BW & 12 & 1.03 & -1.26 & 0.95 & $<<0.001$ & 0.739 & 1.05 & 0.445 \\
\hline PAL & 12 & 0.79 & 0.29 & 0.87 & $<<0.001$ & 0.028 & 0.85 & $0.078^{* *}$ \\
\hline UP & 11 & 0.53 & 1.16 & 0.58 & 0.006 & 0.002 & 0.70 & $0.027^{*}$ \\
\hline TEL & 12 & 1.52 & -3.73 & 0.88 & $<<0.001$ & 0.004 & 1.62 & $<<0.001^{*}$ \\
\hline sw & 10 & 1.14 & -1.01 & 0.96 & $<<0.001$ & 0.094 & 1.17 & $0.028^{*}$ \\
\hline ZH & 10 & 1.22 & -2.40 & 0.76 & $<0.001$ & 0.362 & 1.40 & $0.065^{* *}$ \\
\hline ZW & 10 & 1.47 & -3.90 & 0.79 & $<0.001$ & 0.083 & 1.66 & $0.007^{*}$ \\
\hline 10 & 12 & 1.29 & -2.78 & 0.80 & $<<0.001$ & 0.162 & 1.44 & $0.018^{*}$ \\
\hline OL & 12 & 0.94 & -1.38 & 0.82 & $<<0.001$ & 0.686 & 1.04 & 0.746 \\
\hline OD & 10 & 1.01 & -1.91 & 0.52 & 0.0191 & 0.971 & 1.41 & 0.188 \\
\hline BB & 7 & 1.13 & -2.27 & 0.78 & 0.0080 & 0.623 & 1.28 & 0.217 \\
\hline $\mathrm{OH}$ & 10 & 1.30 & -2.49 & 0.83 & 0.0002 & 0.145 & 1.42 & $0.021^{*}$ \\
\hline POW & 10 & 1.08 & -0.78 & 0.85 & $<<0.001$ & 0.616 & 1.17 & 0.234 \\
\hline ow & 10 & 1.02 & -1.05 & 0.69 & 0.0029 & 0.948 & 1.22 & 0.301 \\
\hline
\end{tabular}

$\log \mathrm{y}=\mathrm{a} \log \mathrm{x}+\log \mathrm{b}$. Least squares regression ( $\mathrm{y}$ on $\mathrm{x}$ ) is not appropriate in this case because it assumes that $\mathrm{X}$ has neither natural variability nor measurement error and has been fixed by the investigator. However, it is still used here for the comparison with the previous study of Abdala \& Giannini (2000). Because both variables have the same units of measurement, major axis regression (MAR) is appropriate, but not the reduced major axis method. For consistency with the previous analysis, both methods are applied here, but our interpretation focuses on the MAR results. Most measurements of the skull were the same as those used by Abdala \& Giannini (2000), where we determined the skull width at postorbital bar (POW). Because most specimens are only partially prepared, some variables could not be determined. When the measurements are available, they also should be treated with caution, because the south Brazilian Triassic fossils usually are deformed (Holz \& Schultz, 1998). If the preservation of one part is too poor, that specific part is not measured. The measurements of the holotype were taken from the table 1 of Barberena (1981) and photographs. The measurements of AD, PD, and TP were not used in the analysis, because only a few values are available (Table 1).

In order to compare with the current analysis, the $\mathrm{P}$ value for isometry also is calculated using the major axis method. The snout length (MUL) does not deviate significantly from isometry $(\mathrm{P}=0.13)$, whereas the height of the zygomatic arch $(\mathrm{ZH})$ deviates barely significantly from isometry $(\mathrm{P}=0.065)$. Most variables other than upper postcanine tooth length
(UP), orbital diameter (OD), and occipital width (OW) are significantly related to the total length of the skull (TL) (Table 2 ). The models explain a large portion of the total variation in dependent variables, with $\mathrm{R}^{2}$ values ranging from 0.52 to 0.95 (most $>0.76$ ). However, the lack of significant correlation between OD and TL is not necessarily true, because the original data are not so accurate due to deformation and lack of enough preparation. Only six variables significantly deviate from isometry $(\mathrm{P}<0.05)$. Same as with Massetognathus pascuali, the facial, orbital components grow more slowly than or at the same rate as the skull, whereas the temporal region grows faster both longitudinally and transversely, except the interorbital distance, which grows faster than the skull.

The height of the zygomatic arch $(\mathrm{ZH})$ also has a similar growth trend in the two species; it is a little bit faster than the growth of the skull. The temporal fenestra enlarges its volume in all three dimensions, so it gives large space for the masseter muscle and temporalis muscle.

The ratio of the interorbital width to the skull length ranges from 0.20 to 0.29 in $M$. pascuali, 0.21 to 0.40 in $M$. ochagaviae. Although this ratio generally is larger in $M$. ochagaviae; this comparison is not for the same size skull. For $M$. pascuali, if the skull grows at same rate as known specimens, the ratio of the interorbital width to the skull length will be greater than that of $M$. ochagaviae when the skull has similar size is similar to that of known specimens of $M$. ochagaviae. When the interorbital region grows relatively wider, the orbits are more laterally rather than dorsally directed.

One distinct feature of this species is its high skull. In most specimens, the occipital height $(\mathrm{OH})$ is more than $40 \%$ of the skull length (TL). In M. pascuali, the ratio of OH to TL generally ranges from 0.22 to 0.30 ; it is greater than 0.30 only in a few specimens, such as the small specimen PVL 4613. However, this ratio is less than 0.31 in the holotype $(0.28)$ and MCP 3871-PV (0.31). If these values are omitted, the positive allometry is not significant. In the materials from the Chañares Formation, the height of the occipital plate grows nearly isometrically with the length of the skull; thus, even if the skulls reach similar size as in $M$. ochagaviae, the ratio of height to length should change little, and the difference in skull height is tenable.

The palate grows at a similar rate as in M. pascuali; although the negative allometric growth is not significant here. The basicranial region grows faster not slower than the skull in whole, although it does not significantly differ from isometric growth. In these specimens, only one specimen (UFRGS-PV0125T) has a ratio of basicranial length to skull length, falling out of the range of $M$. pascuali. Although it has strong impact on the calculated value of a, the value still is greater than 1 even if it is excluded. The size of the postcanine teeth is greater in larger specimen, so they must have been replaced during growth. In the specimens, the upper postcanine number changes little, so that the teeth are lost anteriorly and added posteriorly at almost the same rate. The change in the length of the upper postcanine tooth row is mainly obtained by the enlargement of individual tooth. 
Therefore, it is reasonable that the length of upper postcanine tooth row grows in a negative allometric way compared to the skull as a whole.

To validate two species within Massetognathus by morphometrics, the discriminant analysis is applied here. One major problem here concerns the missing data. If all the variables with missing data were omitted, not enough data would be available for analysis; thus, some missing data in Table 1 are replaced by the data calculated by allometric equation $\mathrm{Y}=\mathrm{b} * \mathrm{X}^{\mathrm{a}}$, using the values of $\mathrm{a}, \mathrm{b}$ in Table 2. Using 12 variables (TL, MUL, OL, TEL, PAL, IO, BW, OD, SW, OH, $\mathrm{OW}, \mathrm{ZH})$, all 12 specimens in Table 1 are separated from the specimens of $M$. pascuali from the Chañares Formation (Figure 9). This shows two species can be discriminated by morphometrics.

When we examined all known Massetognathus materials from Brazil, almost all of them have the same tooth type as $M$. ochagaviae, and can be identified as this species; only one known specimen (MCP 3284-PV) shows the same postcanine tooth pattern as M. pascuali (Figure 9). This specimen was found in Santa Maria Formation in Sanga Pinheiros, $11 \mathrm{~km}$ south of Candelaria, Rio Grande do Sul. It is similar to the holotype of Megagomphodon oligodens (Romer, 1972) with 17-18 relatively small upper postcanines, and thus it was identified as this species by Sá Teixeira (1995).

The classification of MCP 3284-PV as M. pascuali also is supported by the morphometric study. There are nine measurements for this specimen, but because too few values present for variable $\mathrm{BB}$, only 8 variables are used in discriminant analysis. Using these variables, only specimen MCP 3871-PV has a score of 0.71 , and it is not correctly classified. Applying the discriminant equation from these data to specimen MCP 3284-PV groups it with specimens from the Chañares Formation, not other Brazilian specimens.

However, because of the limitation of material (the number of collected specimens, the preservation of specimens), this is a preliminary result and a more conclusive study is needed using more samples.

\section{CONCLUSIONS}

Based on the above description and analysis, these specimens can be clearly differentiated from $M$. pascuali by their greater maximum size, the relatively higher skull with a wide interorbital region, the relatively invariable number of upper postcanines, an isosceles triangular rather than rectangular triangular lateral to the labial ridge in upper postcanines in occlusal view, nearly triangular shaped basin due to the short lingual ridge on upper canines, more vertically inclined coronoid process on mandibles, and subrectangular rather than subquadrate lower postcanines. It is thus valid as a separate species: M. ochagaviae. Some growth trends recognized in this species need to be tested by more and better specimens. The recognition of specimen MCP 3284$\mathrm{PV}$ as $M$. pascuali indicates that two species of Massetognathus coexisted in Brazil, but M. ochagaviae was the dominant one.

\section{ACKNOWLEDGMENTS}

We thank the following for allowing us access to specimens: M.C. Malabarba (MCP) and J. Powell (PVL). The senior author is thankful for discussions with F. Abdala (BPI) and C.L. Schultz (UFRGS). The suggestions from K. Angielczyk and two anonymous reviewers significantly improved this paper.

\section{REFERENCES}

Abdala, F. \& Giannini, N.P. 2000. Gomphodont cynodonts of the Chañares Formation: the analysis of an ontogenetic sequence. Journal of Vertebrate Paleontology, 20:501-506.

Barberena, M.C. 1981. Uma nova espécie de Massetognathus (Massetognathus ochagaviae sp. nov.) da Formação Santa Maria, Triássico do Rio Grande do Sul. Pesquisas, 14:181-195.

Barberena, M.C.; Araujo, D.C. \& Lavina, E.L. 1985. Late Permian and Triassic Tetrapods of southern Brazil. National Geographic Research, 1:5-20.

Battail, B. 1991. Les Cynodontes (Reptilia, Therapsida); une phylogenie. Bulletin du Museum National d'Histoire Naturelle, Section C, 13:17-105.

Bonaparte, J.F. 1963. Descripción del esqueleto poscraneano de Exaeretodon (Cynodontia -Traversodontidae). Acta Geológica Lilloana, 4:5-52.

Bonaparte, J.F. 1966. Una nueva 'fauna' triasica de Argentina (Therapside: Cynodontia: Dicynodontia). Consideraciones filogeneticas y paleobiogeograficas. Ameghiniana, 4:243-296.

Holz, M. \& Schultz C.L. 1998. Taphonomy of the South Brazilian Triassic herpetofauna: fossilization mode and implications for morphological studies. Lethaia, 31:1-12.

Jenkins, F.A. Jr. 1970. The Chañares (Argentina) Triassic reptile fauna; VII, The postcranial skeleton of the traversodontid Massetognathus pascuali (Therapsida, Cynodontia). Breviora, 352:1-28.

Jenkins, F.A Jr. 1971. The postcranial skeleton of African cynodonts; problems in the early evolution of the mammalian postcranial skeleton. Bulletin Peabody Museum of Natural History, 36:1-216.

Romer, A.S. 1967. The Chanares (Argentina) Triassic reptile fauna. III. Two new gomphodonts, Massetognathus pascuali and $M$. terugii. Breviora, 264:1-25.

Romer, A.S. 1972. The Chanares (Argentina) Triassic reptile fauna. XVII. The Chanares gomphodonts. Breviora, 396:1-9.

Sá Teixeira, A.M. 1987. Novas observações osteológicas e taxonômicas sobre Massetognathus ochagaviae Barberena, 1981 (Reptilia, Therapsida, Cynodontia). Paula-Coutiana, 1:39-49.

Sá Teixeira, A.M. 1995. A família Traversodontidae (Therapsida, Cynodontia) no sul do Brasil e suas relações com formas afins no domínio gonduânico. Programa de Pós-Graduação em Geociências, Universidade Federal do Rio Grande do Sul, Doctoral Dissertation, $144 \mathrm{p}$.

Received in April, 2007; accepted in December, 2007. 